در استة نسبة مساهمة زخم بعض أجزاء الجسم من الزخم الكلي

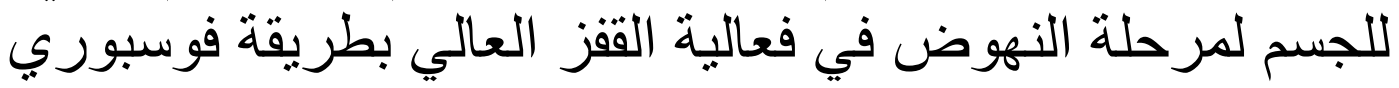

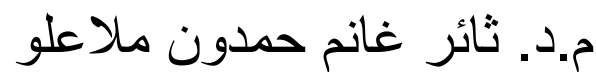
جامعة الموصل / كلية التربية الأساسية

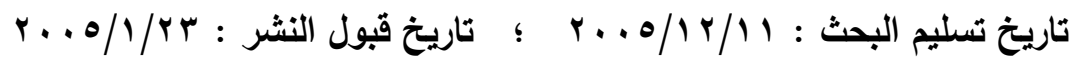

إن لكمية الحركة تأثير كبير على الانجاز خلال مرحلة النهوض في فعالية القفز العالي

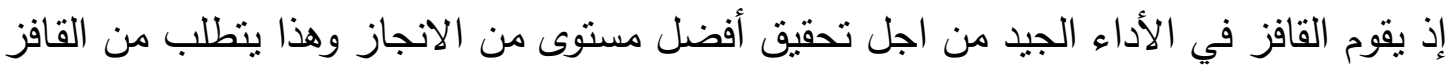

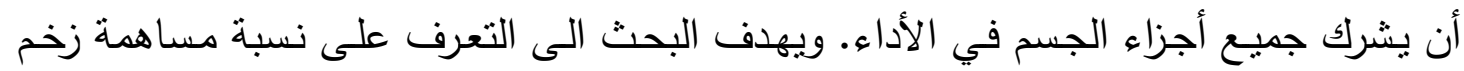
أجزاء الجسم من الزخم الكلي للجسم لمرحلة النهوض في فعالية القفز العالي بطريقة فوسبوري.

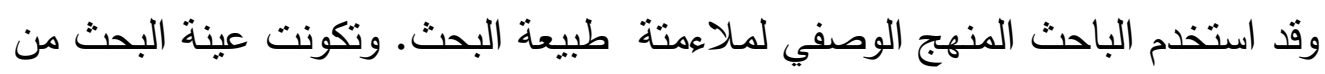

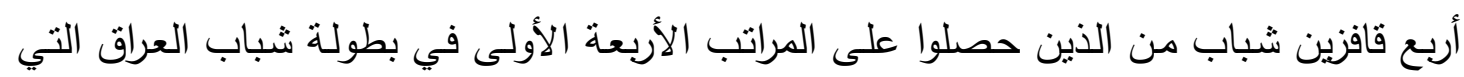

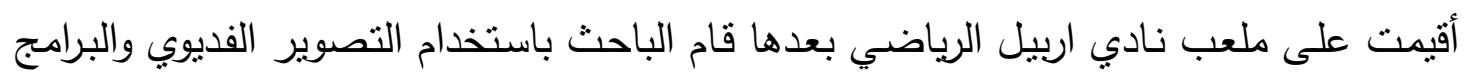

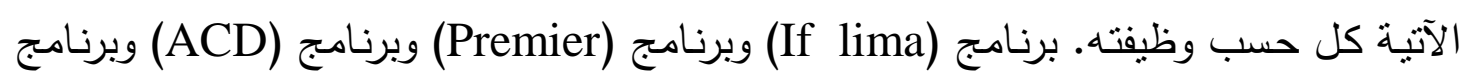

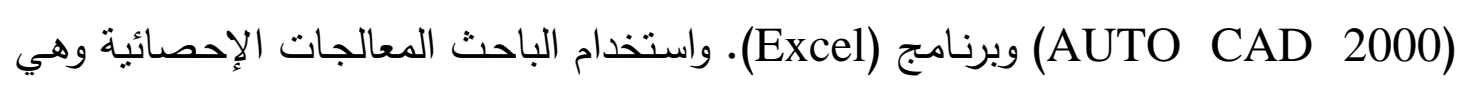
الوسط الحسابي والانحراف المعياري ونسبة المساهمة. وتوصل الباحث الى أن زخم الرجل القائدة جاء في المرتبة الأولى بنسبة مساهمة قدرها

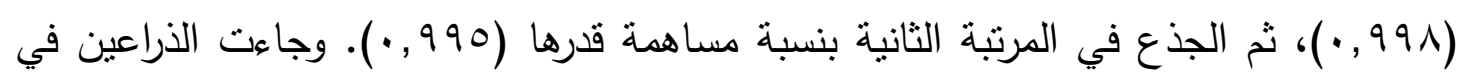

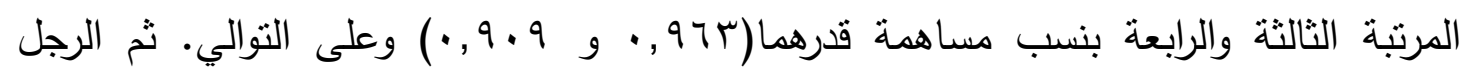
الناهضة بنسبة مساهمة قدرها (AN1, ·)، وحل الرأس في المرتبة الأخيرة بنسبة مساهمة قدرها $\cdot(\cdot, \wedge \circ \mathrm{V})$ 


\section{Study of contribution rate for the main body momentum of the total momentum through take off in high jump Fosbury style}

\section{Lecturer Dr. Thaer Ganem Mala Alow \\ University of Mosul - College of Basic Education \\ Abstract:}

Movement quality greatly affect performance through take off in high jump activity. The athlete make good performance to achieve the best and this requires the participation of all body parts in the performance. The study aims at Identifying the main body momentum of the total momentum through take off in high jump Fosbury style.

The researcher has used the descriptive method for its appropriates. The study sample consists of four jumpers who obtained the first ranks in Iraqi Youth Championship held at Erbil. Sport Club Team Stadium. Then the researcher used the following software: I-film, Premier, ACD See, AUTO CAD 2000 and Excel. The researcher also used statistical tools including mean, standard deviation and contribution ratio.

The study concluded that the leading leg occupied the first rank with a ratio $(0.998)$, then the trunk with a ratio $(0,995)$, then the two arms with a ratio $(0,963,0,909)$ respectively, then the take off leg with a ratio $(0,881)$. The head was the last with a ratio $(0,857)$.

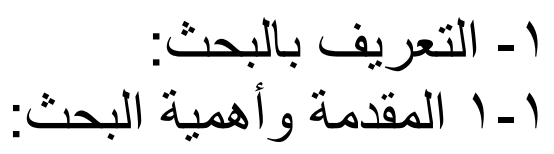

الققز العالي إحدى فعاليات القفز في العاب الساحة والمضمار وهي تقسم الى أربع مراحل

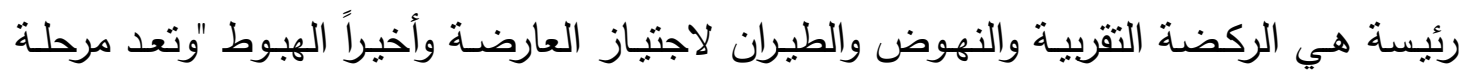
النهوض القسم الرئيس للحركة"(محمد، 919 (، 11 (1) وهي "مرحلة مهمة جداً كونها حلقة الوصل بين الركضة التقربية والطبران، كما إنها المرحلة التي يسلط الرياضي فيها اكبر مقدار من القوة والسرعة على الأرض، يحصل على رد الفعل وفق قانون نيوتن الثالث (لكل فعل رد فعل يساويه

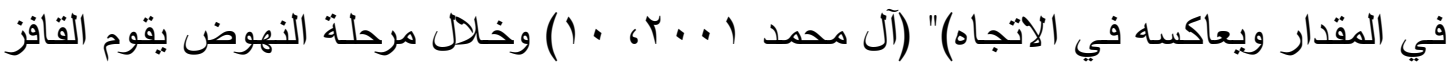
في الأداء الجيد من اجل تحقيق أفضل مستوى من انجاز مرحلة النهوض وهذا ينطلب من القافز 


$$
\text { أن يشرك جميع أجزاء الجسم في الأداء. }
$$

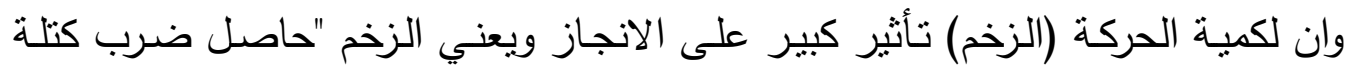

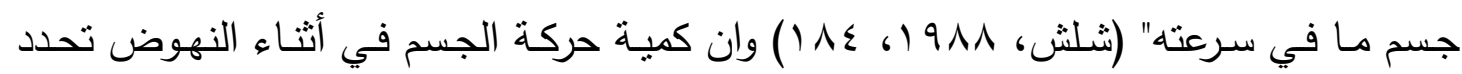

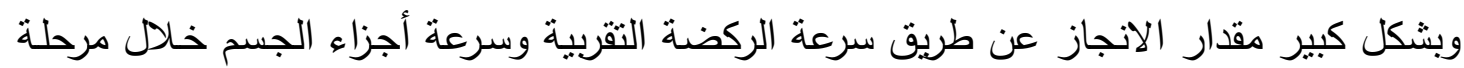

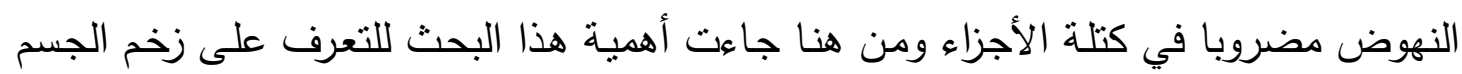

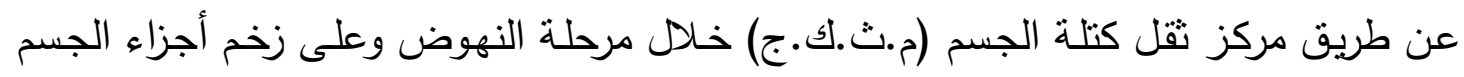

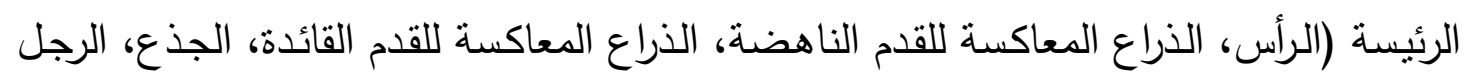
القائدة، الرجل الناهضة) ثم التعرف على نسبة مساهمة زخم الأجزاء من الزخم الكلي للجسم.

\section{1- مشكلة البحث:}

يعد النهوض الجزء الرئيس والمهم في فعالية القفز العالي وهو الذي يعتمد علية بشكل

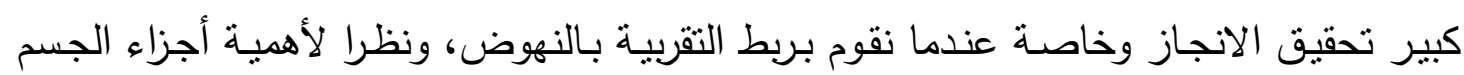

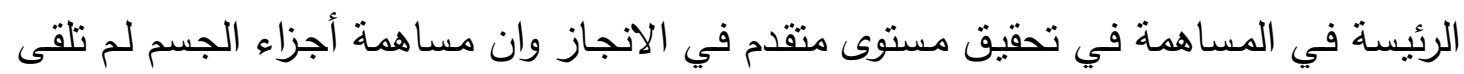

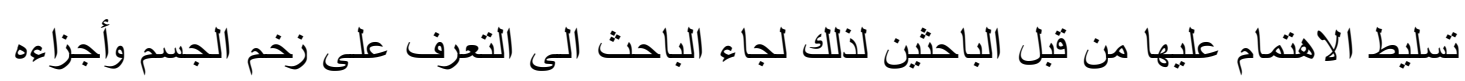
لمعرفة نسبة مساهمة الأجزاء من الكل. فئل

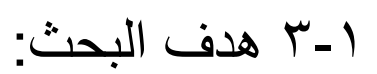

التعرف على نسبة زخم بعض أجزاء الجسم الرئيسة من الزخم الكلي للجسم في مرحلة النهوض لفعالية القفز العالي بطريقة فوسبوري.

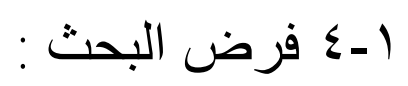

هناك تفاوت بين نسبة زخم بعض أجزاء الجسم الرئيسة من الزخم الكلي في مرحلة النهوض

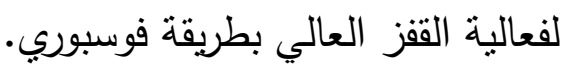

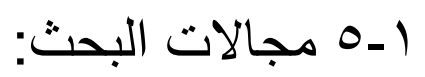

1-0-1 المجال البشري: أربع لقافزين من المشاركين في بطولة الثباب العراقية لعام ه ـ. ـام.

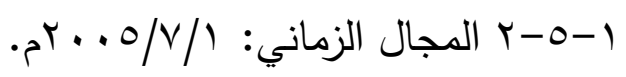

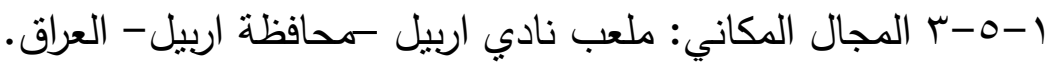




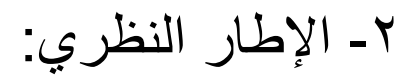

r- ا - الأداء الفني و الميكانيكي لفعالية القفز العالي بطريقة فوسبوري:

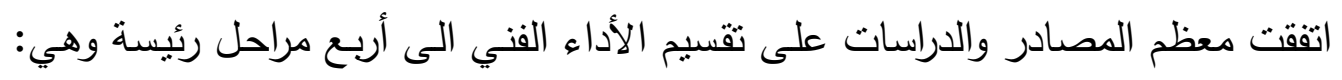

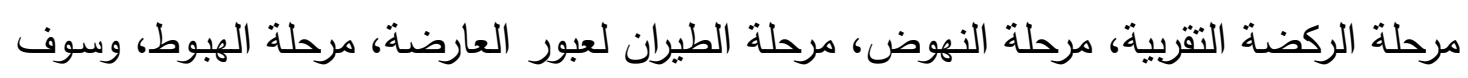
نتطرق بشكل اكبر الى مرحلتي الركضة النقربية والنهوض:

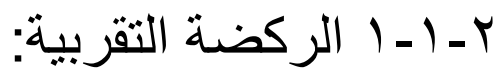

وتودي الركضة التقربية بطريقة فوسبوري على شكل الحرف ( J ) وتكون على شكل خط

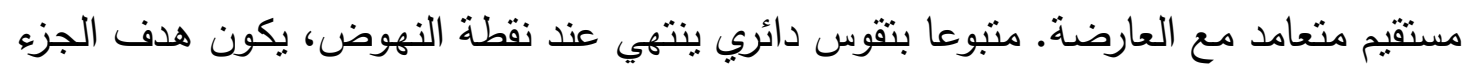

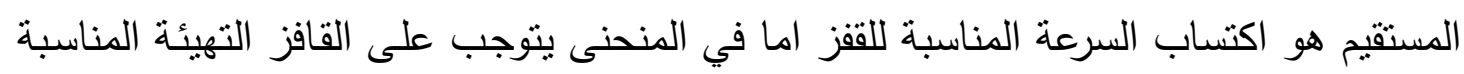
لأداء مرحلة النهوض. (Jacoby and Fraley, 1995, 91-92)

إن الهدف من الركضة النقربية هو زيادة السرعة وتحقيق أفضل ارتفاع للركبة والثأكيد

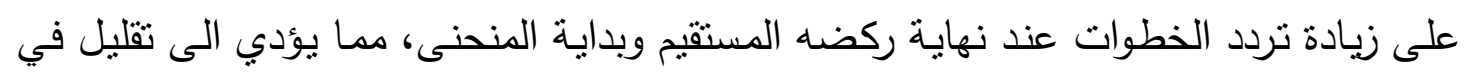

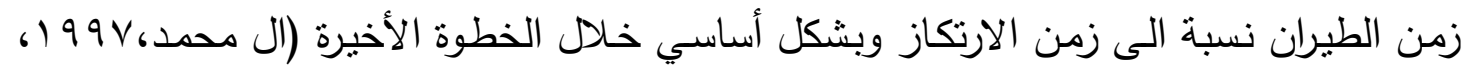

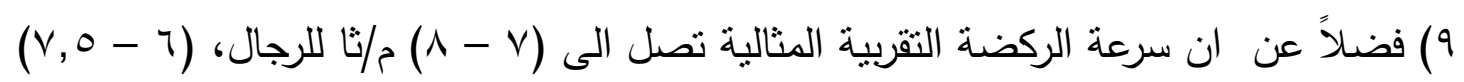

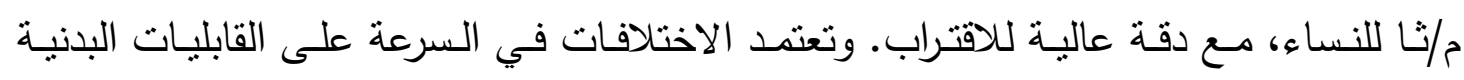

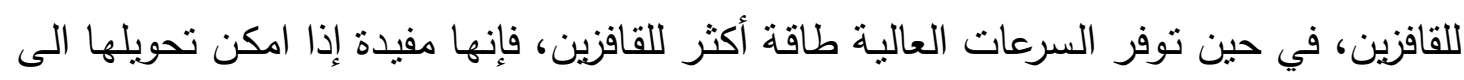

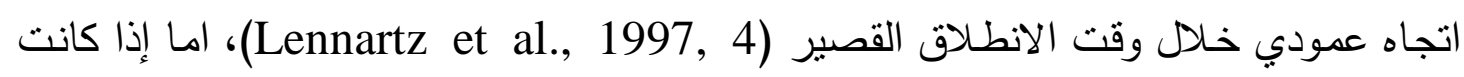

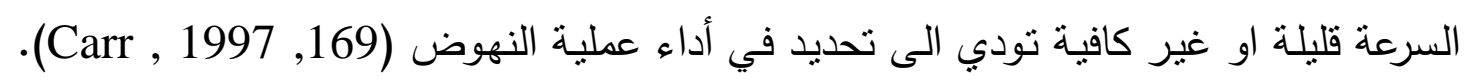

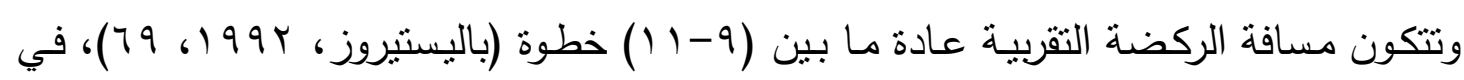

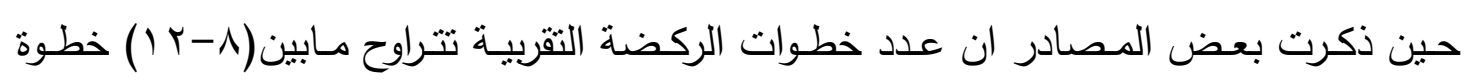

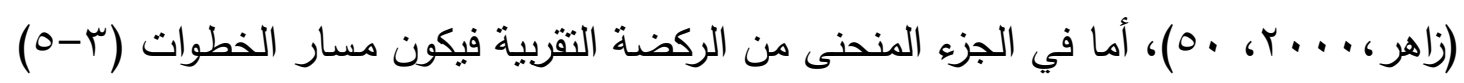

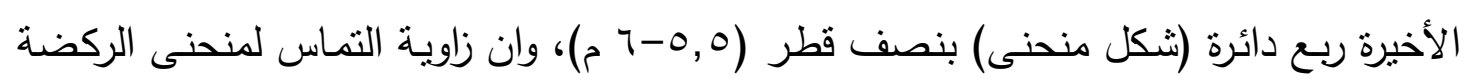

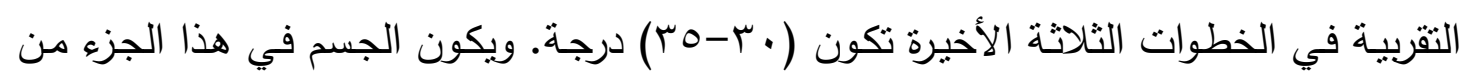

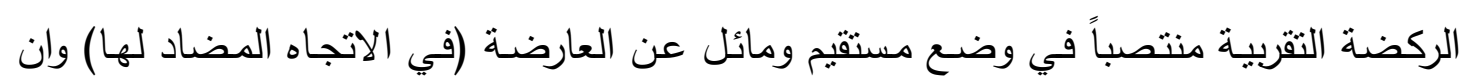

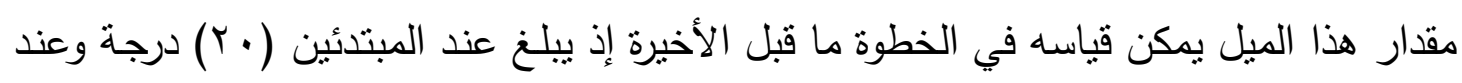

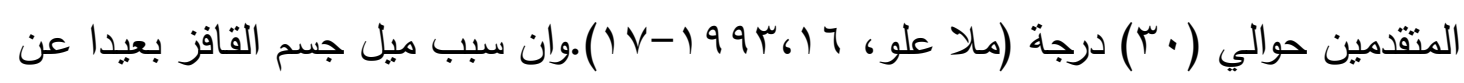

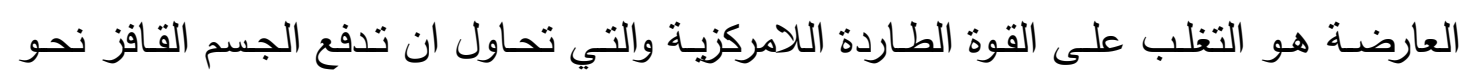

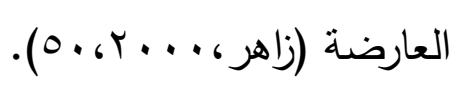


تبدءا مرحلة النهوض من اللحظة التي تلامس القدم الناهضة للقافز الأرض عند نهاية

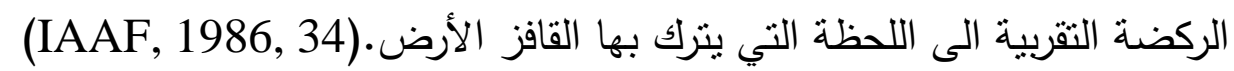

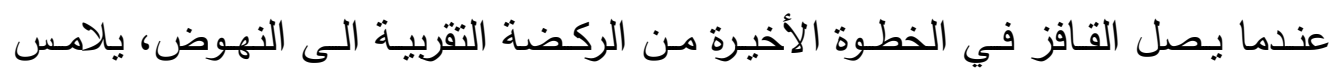

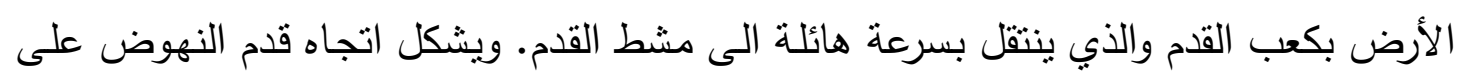

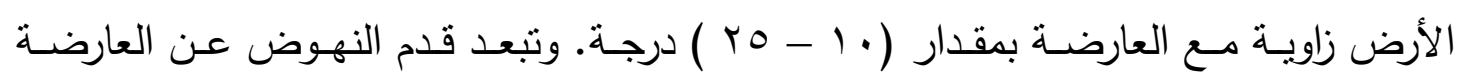

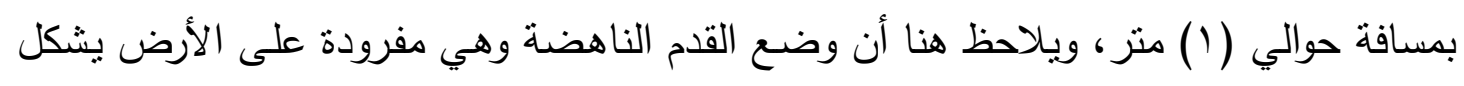
عملية توقف (للرجل الناهضة فقط) تؤدي الى تخفيض السرعة المكتسبة من الركضة التقربية

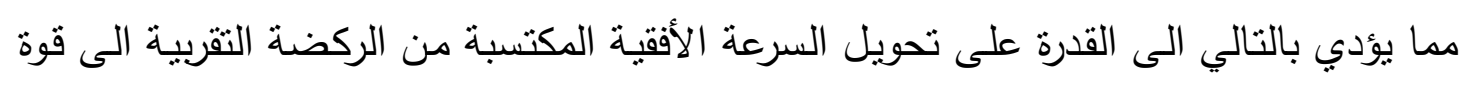

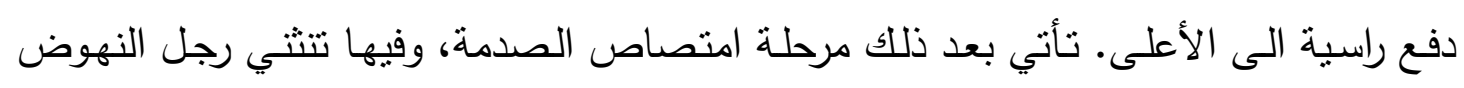

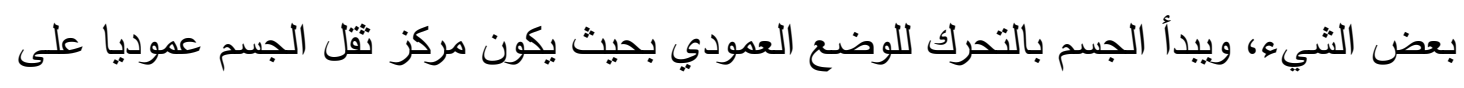
قدم النهوض. وتعد عملية التحضير للنهوض من أهم مراحل الحركة والتي تتحكم بدرجة كبيرة

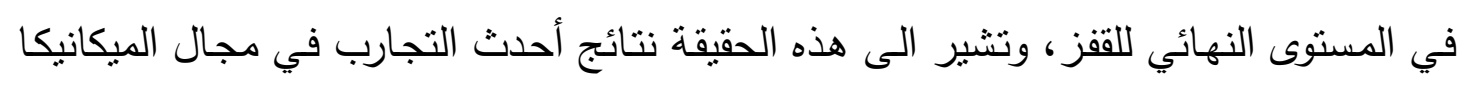

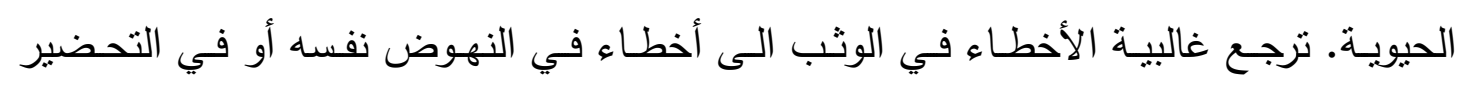

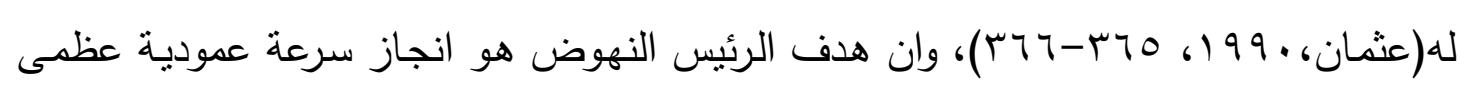

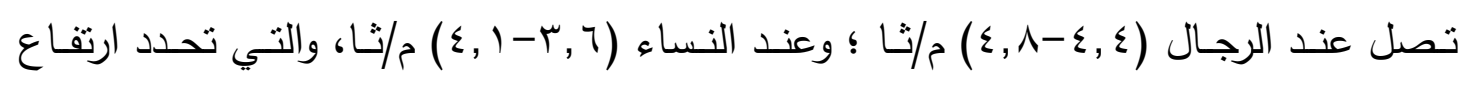

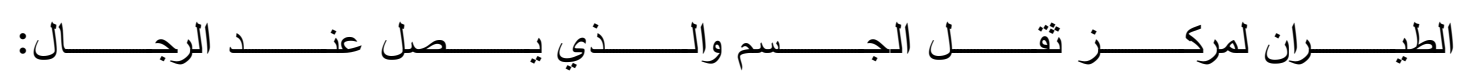

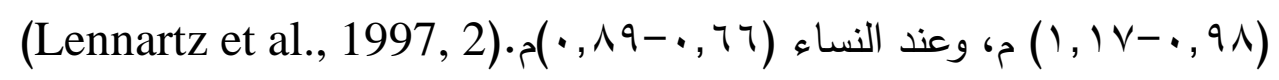

Y - ا ـ الطير ان لعبور العارضة: بعد انتهاء مرحلة النهوض ينحرك القافز في اتجاه الأمام الأعلى بحيث يدور محور

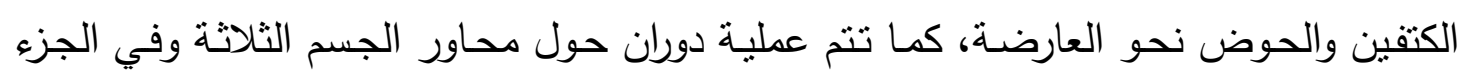

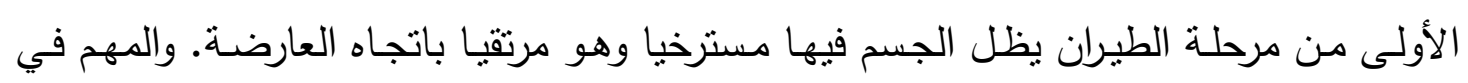

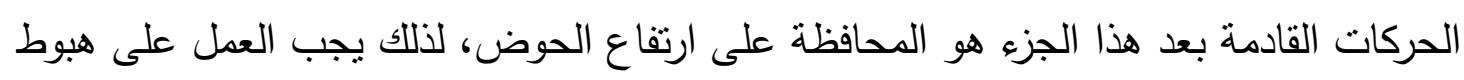

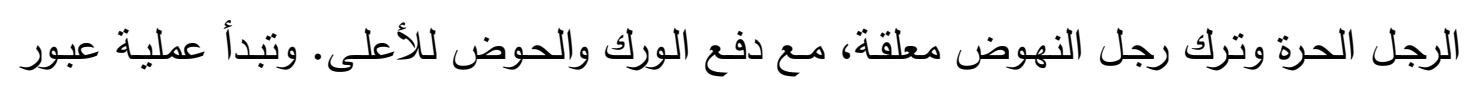

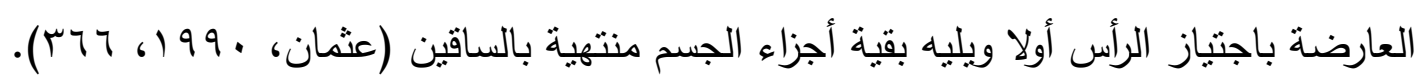

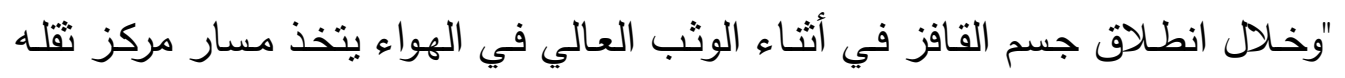

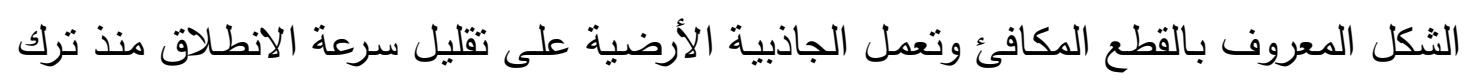

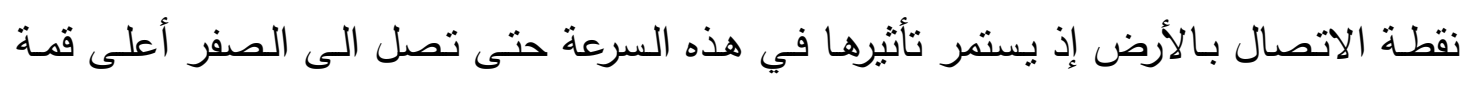

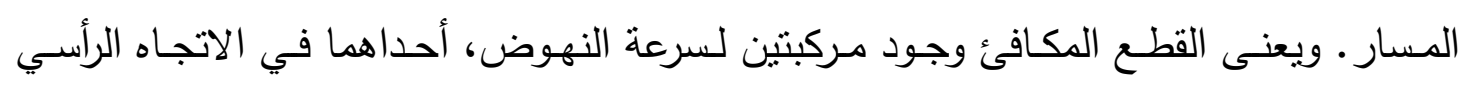


والأخرى في الاتجاه الأفقي وتحدد زاوية النهوض مقدار كل من هاتين المركبتين. وتجدر الإثـارة

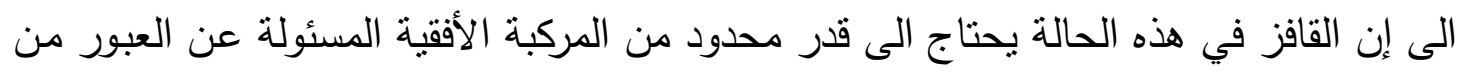

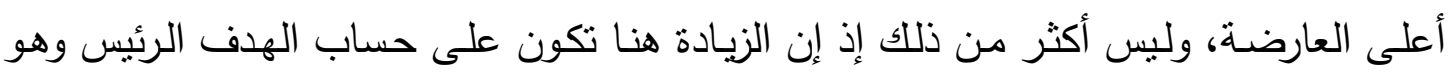

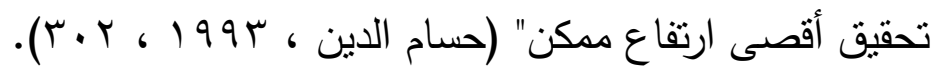

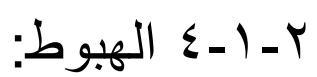

تتم عملية الهبوط على الكتقين، وتبدأ بثني مفصل الحوض ومد مفصل الركبة، وتتم هذه

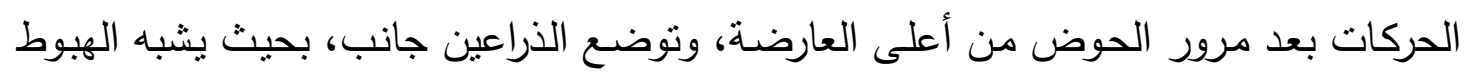

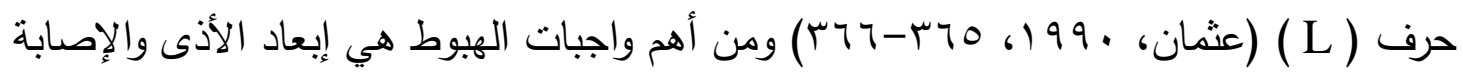

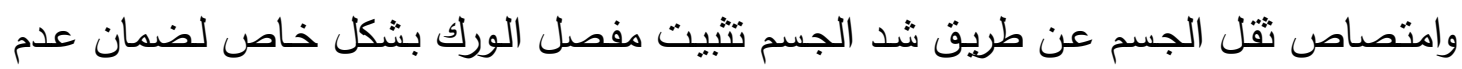

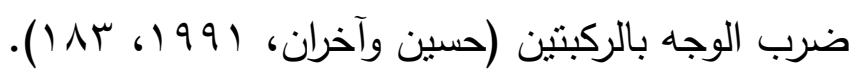

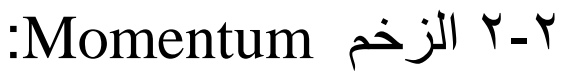

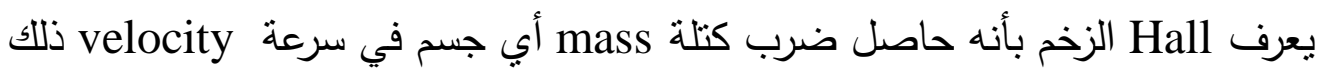
الجسم ويرمز له بالحرف الكبير M ليصبح القانون كما يأتي: $\mathrm{M}=\mathrm{mv}$

ووحدة قياس الزخم هي كيلوغرام-متر/ثانية (kg.m/s). (Hall, 1999, 411) ويعد الزخم من الكميات المتجه لأنه يأني من حاصل ضراب كمرام كيتان أحداهما متجه وهي السرعة والأخرى قياسية وهي الكتلة.

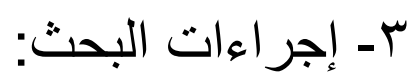

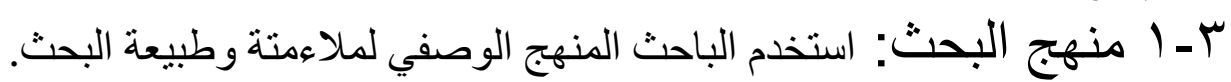
r-r

تكونت عينة البحث من أربع قافزين من الذين حصلوا على المراتب الأربعة الأولى في

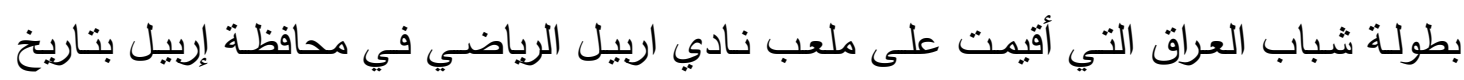

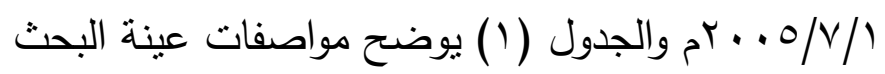


(1) الجدول (1)

يوضح مواصفات عينة البحث

\begin{tabular}{|c|c|c|c|c|}
\hline العمر الزمني & الكتلة & الطول & الانجاز & العينة \\
\hline • r سنة & TYYTغ & 9 9 اسم & 9 9 اسم & داون \\
\hline r. & . & 99 اسم & و اسم & عدي \\
\hline r r سنة & & 9 1) اسم & م1 اسم & هولكر \\
\hline 19 سنة & . Vكغ & V V اسم & ، 1اسم & محمد \\
\hline
\end{tabular}

ب- ب الأجهزة و الأدوات:

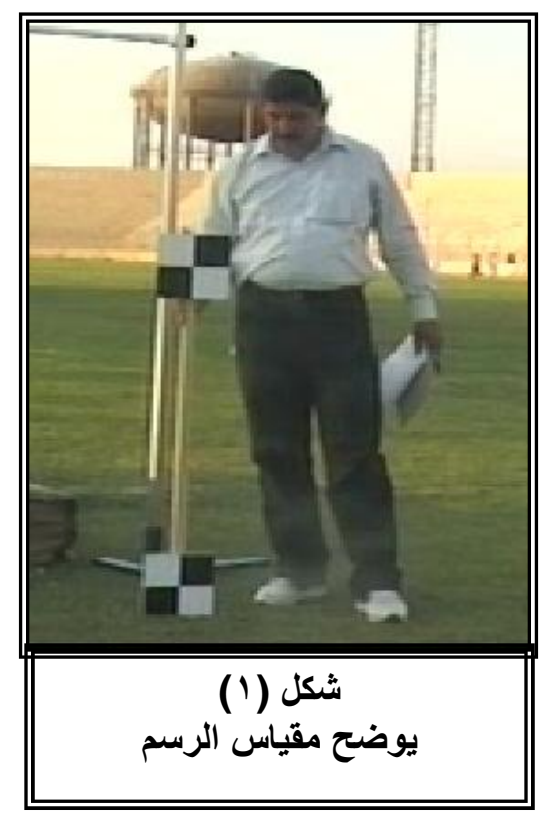

استخدم الباحث الأجهزة والأدوات الآتية من اجل الحصول على أفضل دقة البيانات:

• آلة تصوير فيدوية عدد ( 1 ( ) نوع (Sony). شريط فيديوي عدد ( 1 )نوع (Sony).

$$
\text { جهاز حاسوب. }
$$

قرص ليزري نوع (Skc).

مقياس رسم ( بطول ( منر) شكل (1).

شريط قياسي.

حامل لنتبيت الة التصوير .

جهاز الققز العالي مع ملحقاته.

\section{ب- أدو ات البحث:}

استخدم الباحث الملاحظة العلمية التقنية بوساطة الحاسوب وسائل لجمع البيانات.

\section{بـ إجر اعات التجربة الميدانية :}

تم تصوير تجربة البحث يوم الجمعة الموافق / / / ه . . ب في تمام الساعة (0) عصراً

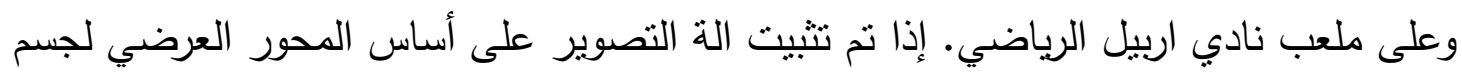

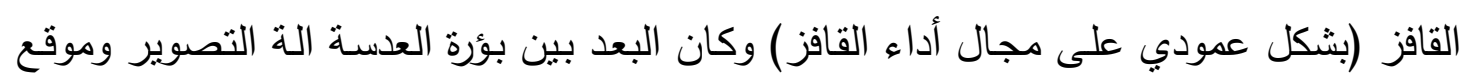

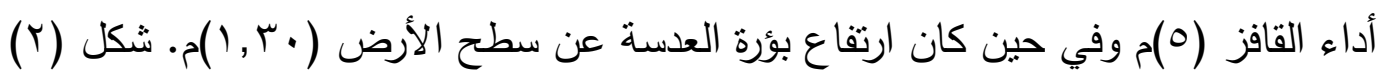




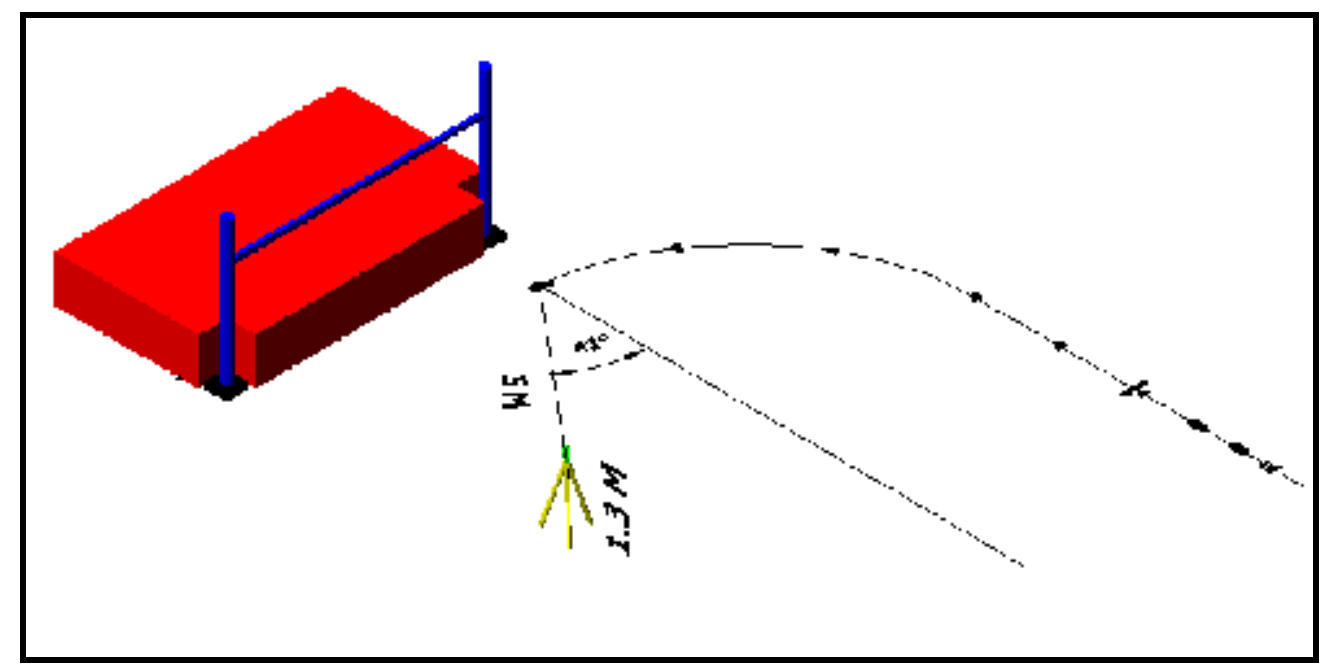

شكل (r) (r)

يوضح موقع الة التصوير

r-ד البر امج المستخدمة في التحليل: ان التحليل بثكل عام هو وسيلة لتجزئة الحركة الكلية الى أجزاء ودراسة هذه الأجزاء

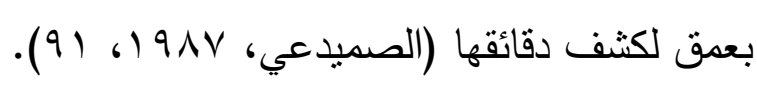

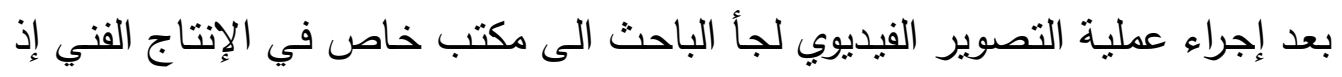

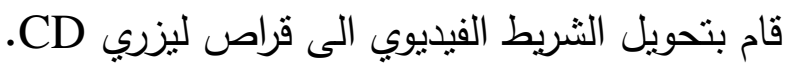

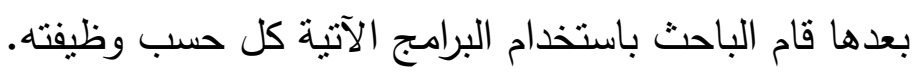

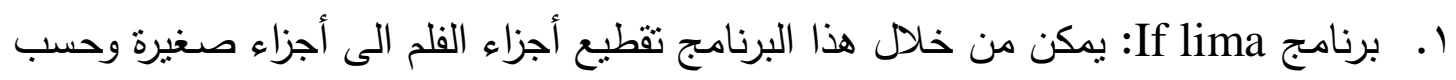

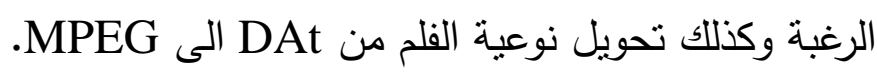

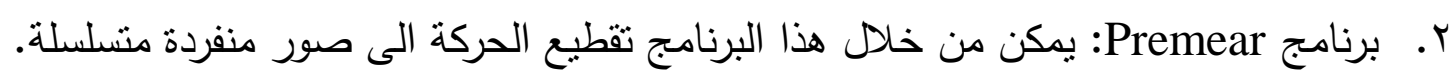

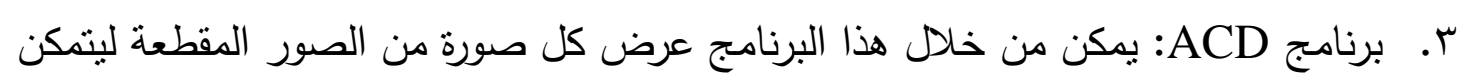

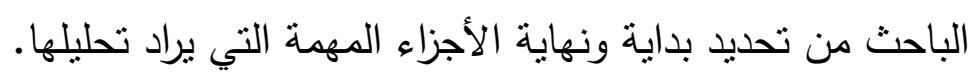

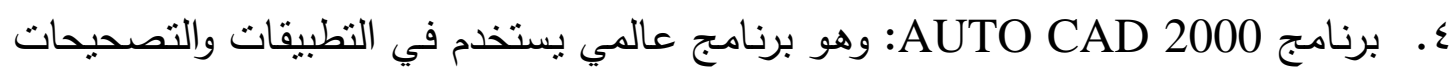

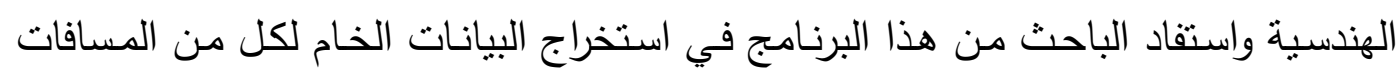
والإبعاد والارتفاعات لكل صورة بمفردها. 0. برنامج Excel: وهو الحد برامج Office واستفاد الباحث من هذا البرنامج في معالجة

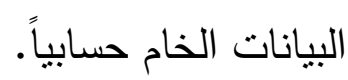




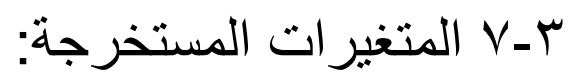

ه الدسارات: تمكن الباحث من القياس الحقيقي للمسارات والتي كانت على شكل منحنى دون

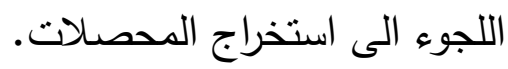

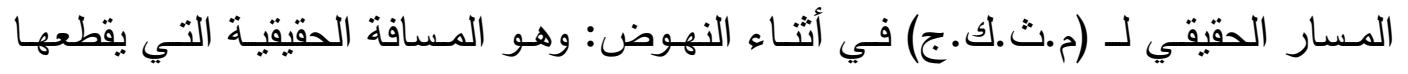

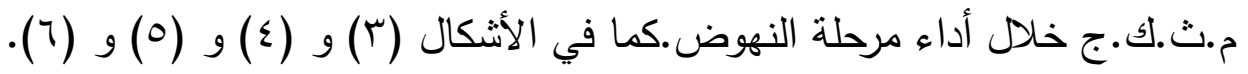

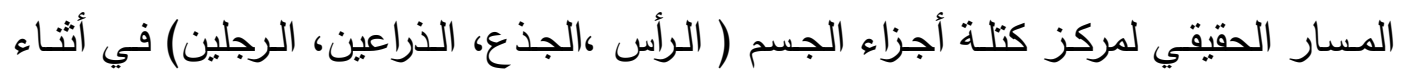

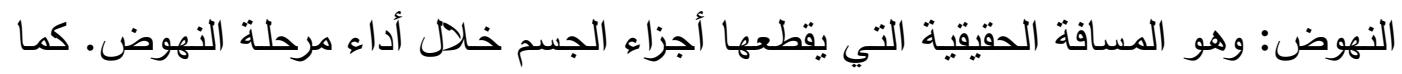

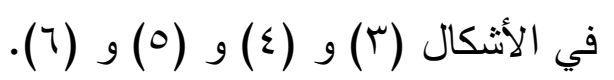

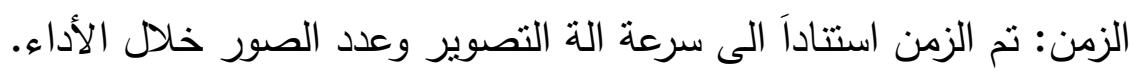

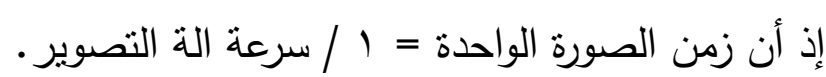

زمن الأداء = زمن الصورة الواحدة × (عدد الصورة خلال الأداء - ( ).

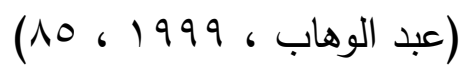

متوسط السرعة : تم احتساب متوسط السرعة من خلال القانون الاتي :

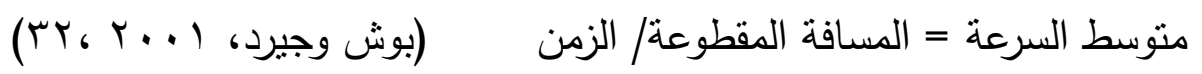

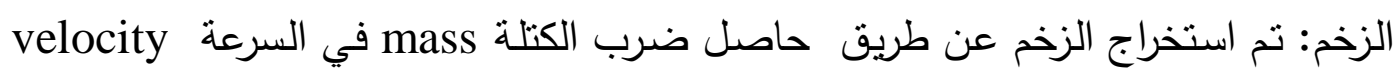

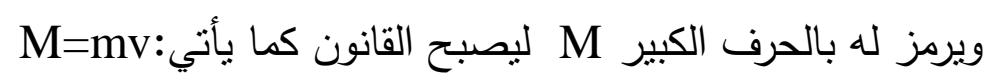

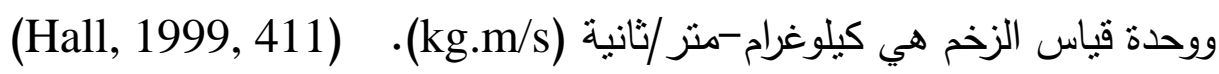

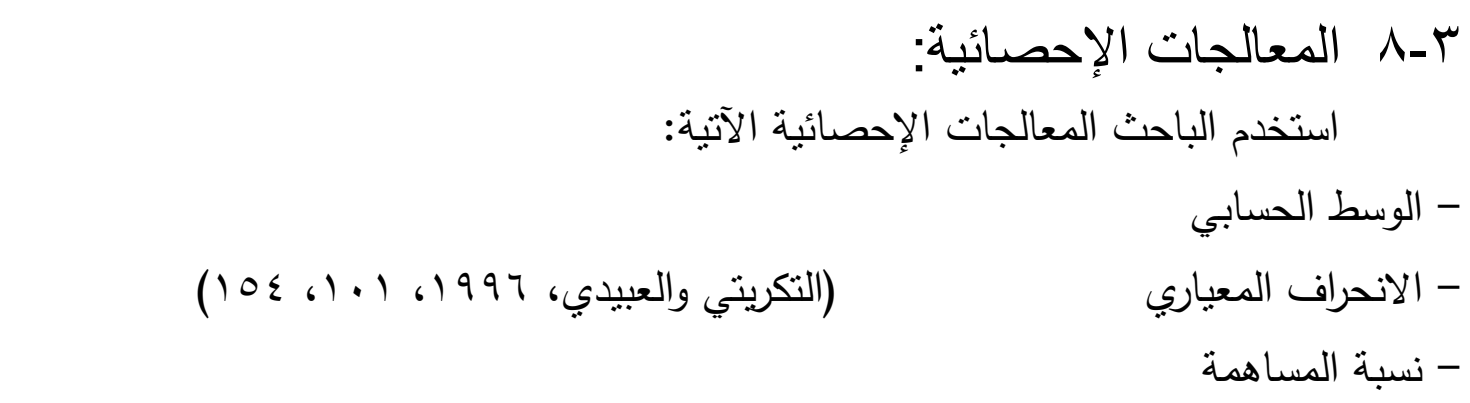

وقد تم استخدام الحاسوب الآلي لغرض معالجة البيانات إحصائيا باستخدام برنامج

.(SPSS) 


\section{ـ - عرض نتائج البحث ومناقتشتها:}

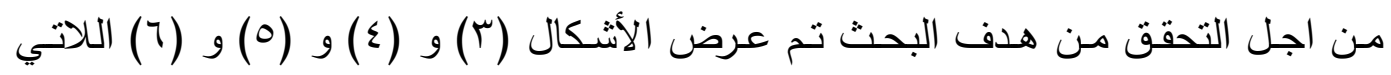

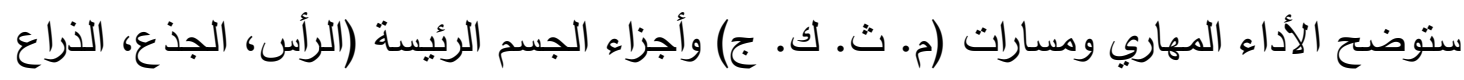

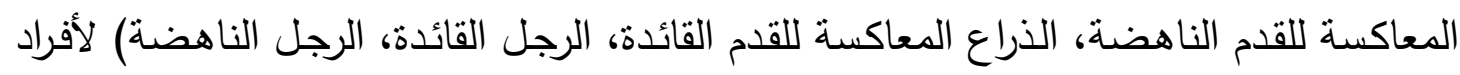

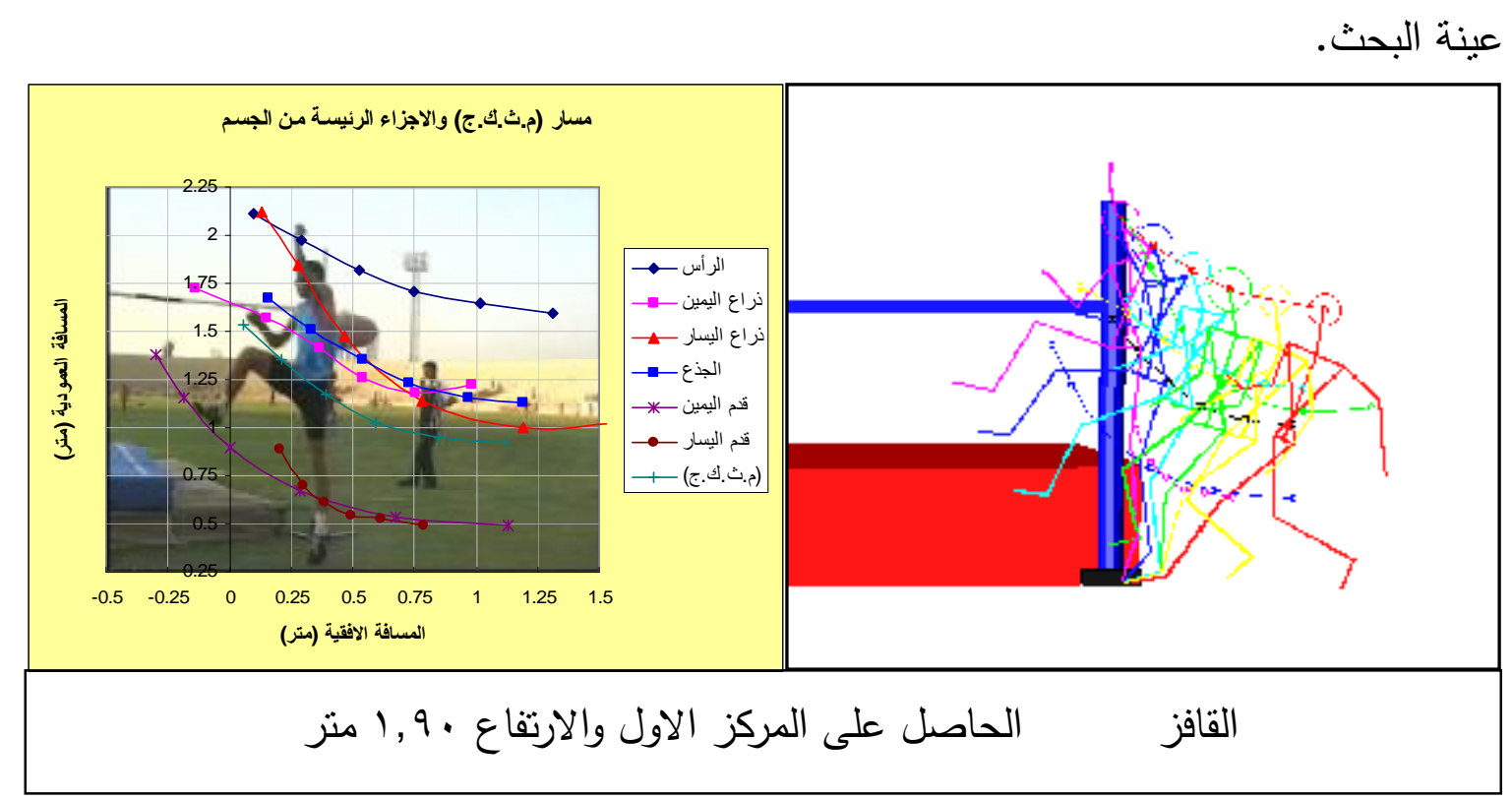

شكل (r)

يوضح الأداء المهاري ومسارات (م.ث.ك.ج) والأجزاء الرئيسة لأحد افراد عينة البحث

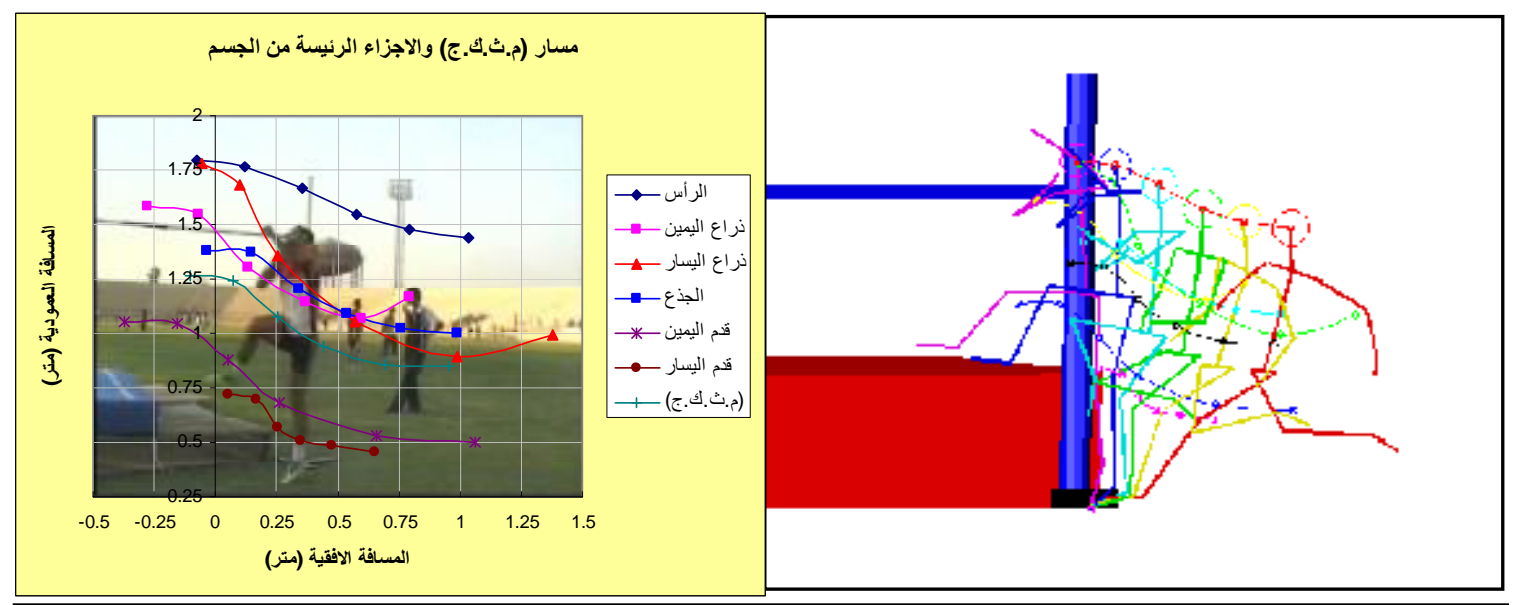

القافز عدي أياد الحاصل على المركز الثاني والارتفاع •9, 9 مثز

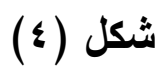

يوضح الأداء المهاري ومسارات (م.ث.ك.ج) والأجزاء الرئيسة لأحد افراد عينة البحث 


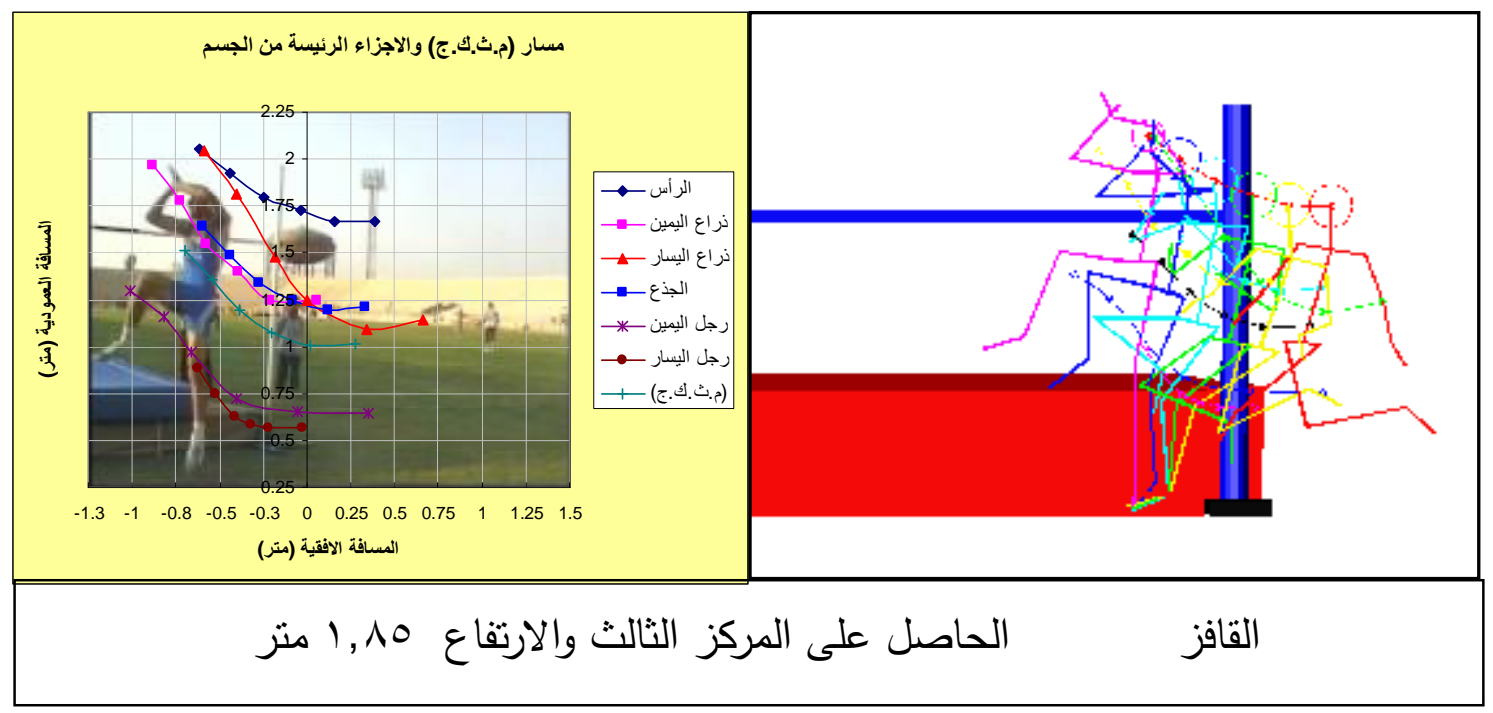

\section{شكل (0)}

يوضح الأداء المهاري ومسارات (م.ث.ك.ج) والأجزاء الرئيسة لأحد افراد عينة البحث

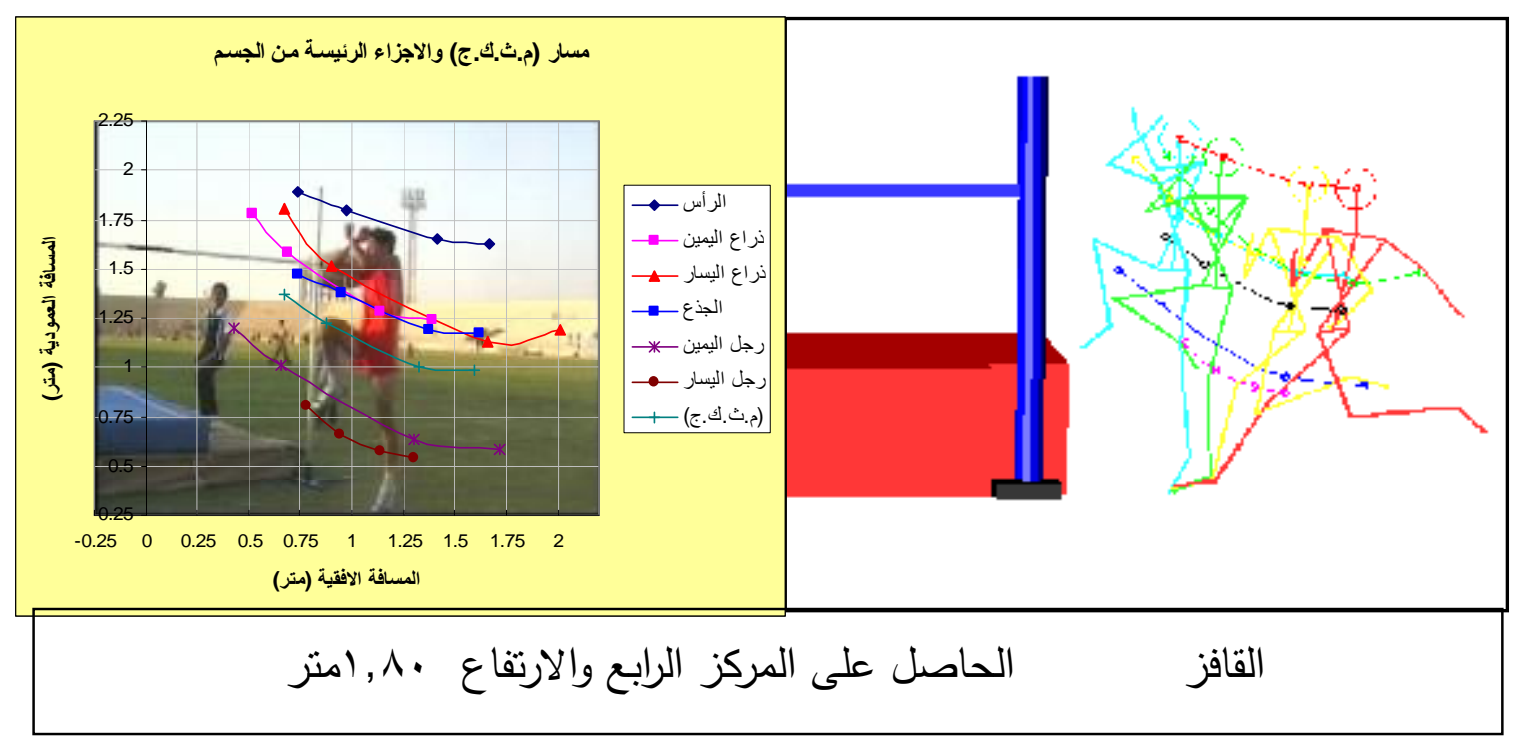

شكل (7)

يوضح الأداء المهاري ومسارات (م.ث.ك.ج) والأجزاء الرئيسة لأحد افراد عينة البحث 
جدول (r)

يوضح مقار مسار (م.ث.ك. ج) الجسم وأجزاء الجسم الرئيسة بالمتر لإفراد عينة البحث

\begin{tabular}{|c|c|c|c|c|c|c|}
\hline انحراف & وسط & $\varepsilon$ & $r$ & r & 1 & الجسم وأجزاءه \\
\hline., 11 & $1,1 \mathrm{~V}$ & 1,11 & $1, \cdot r$ & $1, r 9$ & 1,17 & الجسم \\
\hline., 10 & 1,10 & 1,11 & $\cdot, 9 \mathrm{~V}$ & $1, r \varepsilon$ & 1,11 & رأس \\
\hline., 11 & $1, .9$ & 1,ir & $\cdot, 90$ & l, r. & $1, \cdot 1$ & جذع \\
\hline., 11 & I,rT & $1, Y \wedge$ & $1, \cdot v$ & $1, r 9$ & I, YV & اللقدم الناهضة المعاكسة \\
\hline., 19 & l,A. & 1,10 & $1,7)$ & $r, \cdot \varepsilon$ & l, v. & اللقدم القائدة المعاكسة \\
\hline., $1 \varepsilon$ & $1, \pi$ & 1,7 & $1, \varepsilon V$ & 1,11 & 1,71 & قدم يمين \\
\hline$\cdot, \cdot V$ & $\cdot, \mathrm{V}$. & $\cdot, 79$ & $\cdot, 7$ & $\cdot, \times 4$ & $\cdot, V \varepsilon$ & قدم يسار \\
\hline
\end{tabular}

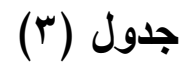

يوضح مقدار سرعة الجسم وأجزاء الجسم الرئيسة بالمتر/ثا لإفراد عينة البحث

\begin{tabular}{|c|c|c|c|c|c|c|}
\hline انحراف & وسط & ؛ & $r$ & $r$ & 1 & الجسم وأجزاءه \\
\hline$\cdot, V Y$ & $0, r q$ & $\varepsilon, 9 \varepsilon$ & $7, \varepsilon 1$ & $0, r \wedge$ & $\varepsilon, \wedge r$ & الجسم \\
\hline 4T, & $0, r$. & $\varepsilon, q$. & $7, \cdot V$ & 0,7 & $\{, 7)$ & رأس \\
\hline$\cdot, 70$ & $0, \cdot \varepsilon$ & $\varepsilon, v$. & 0,90 & $0, .1$ & $\varepsilon, \varepsilon \wedge$ & جذع \\
\hline$\cdot$, TV & $0, \pi V$ & $0, r \varepsilon$ & $7, T V$ & $0, r_{\Lambda}$ & $0, Y \Lambda$ & اللقداع الناهضة المعاكسة \\
\hline $1, Y \wedge$ & $\Lambda, r \varepsilon$ & $v, v_{1}$ & $1 ., .0$ & $\wedge, \varepsilon 9$ & $v, .9$ & اللذراع المائية \\
\hline 1,17 & $v$, or & 7,79 & 9,17 & $v, \infty 0$ & $7, \times 1$ & قدك يمين \\
\hline$\cdot$, , & $r, r^{T}$ & $r, \wedge \Lambda$ & $r, v r$ & $r, 11$ & $r, \cdot q$ & قدم يسار \\
\hline
\end{tabular}




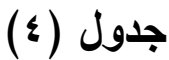

يوضح مقدار زخم الجسم وأجزاء الجسم الرئيسة لإفراد عينة البحث

\begin{tabular}{|c|c|c|c|c|c|c|}
\hline انحراف & وسط & $\varepsilon$ & $r$ & $r$ & 1 & الجسم وأجزاءه \\
\hline $7 \cdot, r q$ & דq, & $r \leq 0, \wedge$ & $\varepsilon \Lambda \cdot, \vee \vee$ & rVT, & r", & الجسم \\
\hline$r, r q$ & YV, IT & $Y \varepsilon, Y)$ & rq, q1 & $r \cdot, r$ & $r \varepsilon, \varepsilon$. & رأس \\
\hline$I V, \leqslant 0$ & $107,1 \mathrm{r}$ & $1 \leq \cdot, \leq 9$ & $I V \vee, \wedge 0$ & $17 r, O r$ & $1 \leq r, \pi r$ & جذع \\
\hline$r, 07$ & $r 7,7 \tau$ & $r \leqslant, r \leqslant$ & $r \cdot, r \varepsilon$ & Y,$\leqslant \wedge$ & Yo, TV & للقام الأراع المعاكسة \\
\hline $0, \leqslant 1$ & $r q, r r$ & $r \varepsilon, 9 \wedge$ & $\leqslant 0,7$. & $\{1, \wedge 1$ & $\Gamma \varepsilon, \varepsilon \wedge$ & اللقراع المعاكسة \\
\hline$|\leq, \Gamma|$ & $1 \cdot 1, \wedge \mathrm{V}$ & $\wedge V, r \leq$ & $119,0$. & $1 \cdot 7,19$ & qr, & قدم يمين \\
\hline$\varepsilon, V \vee$ & $\varepsilon r, V T$ & rV, Tr & $\varepsilon 9,1$. & $\leqslant 0,0$ & LT, & قدم يسار \\
\hline
\end{tabular}

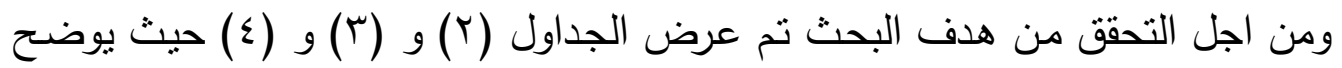

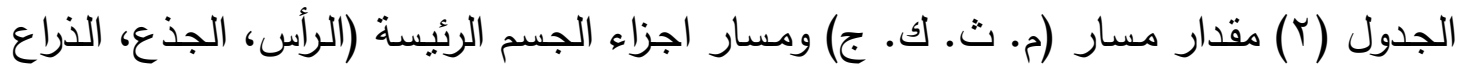

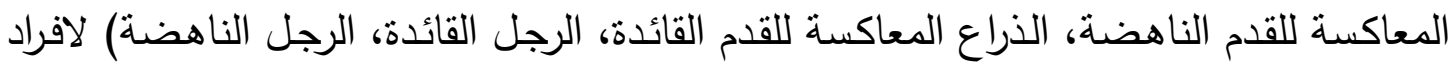

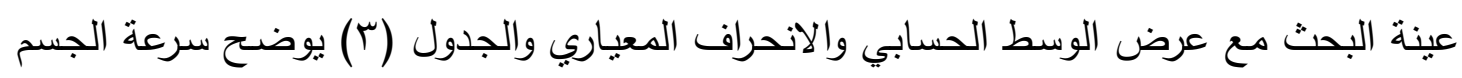

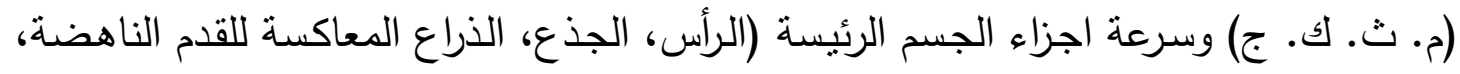

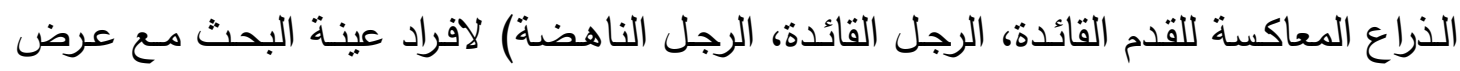

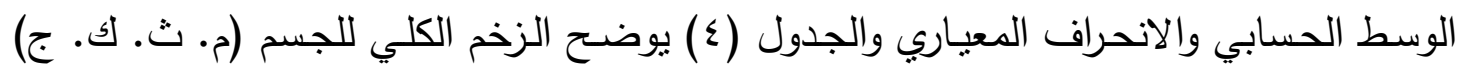

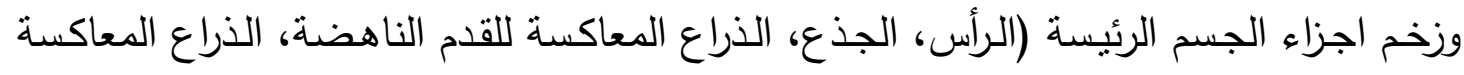

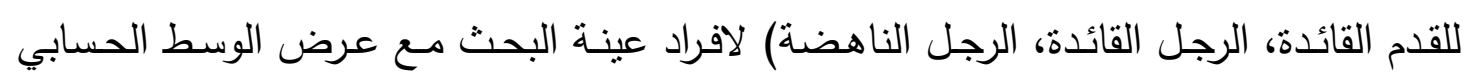

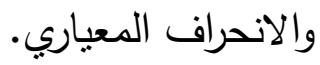

ولكي نتحقق من هدف البحث الذي نص على: (التعرف على نسبة زخم اجزاء الجسم الرئيسة من الزخم الكلي في اثثاء النهوض لفعالية القفز العالي بطريقة فوسبوري).

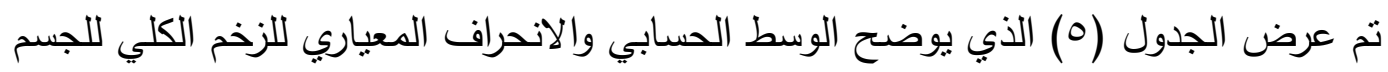

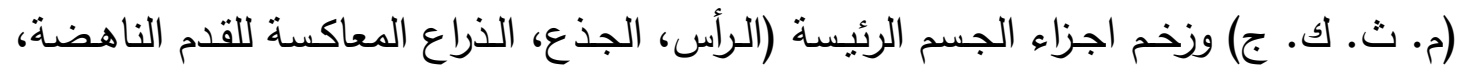

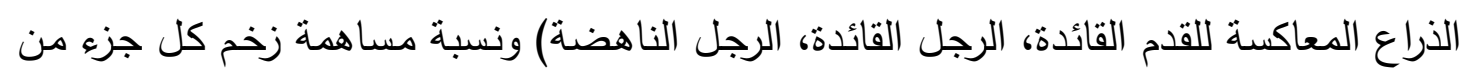
اجزاء الرئيسة من الزخم الكلي للجسم. 
جدول (•)

يوضح الوسط الحسابي والانحراف المعياري لزخم الجسم وأجزاء الجسم الرئيسة ونسبة المساهمة

\begin{tabular}{|c|c|c|c|}
\hline نسبة المساهمة & الانحراف المعياري & وسط حسابي & الجسم وأجزاءه \\
\hline$\cdot, 991$ & $|\varepsilon, \Gamma|$ & $1 \cdot 1, \wedge \mathrm{V}$ & الرجل القائدة \\
\hline$\cdot, 990$ & $1 v, \varepsilon 0$ & $107,1 \mathrm{r}$ & جذع \\
\hline ( & $0, \sum 1$ & $r q, Y r$ & الذراع المعاكسة للقدم القائدة \\
\hline$\cdot, 9 \cdot 9$ & Y,OT & YT, & الذراع المعاكسة للقدم الناهضة \\
\hline$\cdot, \wedge \wedge)$ & $\varepsilon, \vee \vee$ & $\varepsilon r, V T$ & قدم يسار \\
\hline$\cdot, \wedge \circ \mathrm{V}$ & $r, r q$ & $r V, 1 T$ & رأس \\
\hline
\end{tabular}

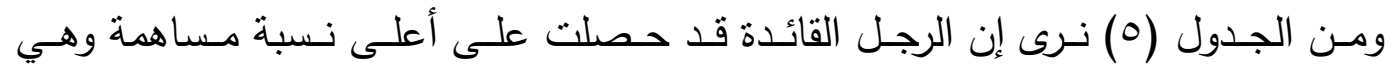

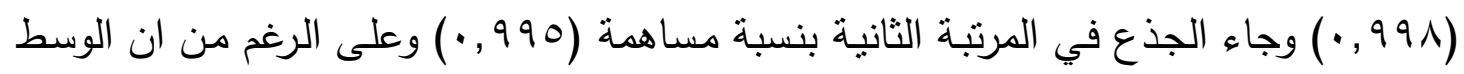

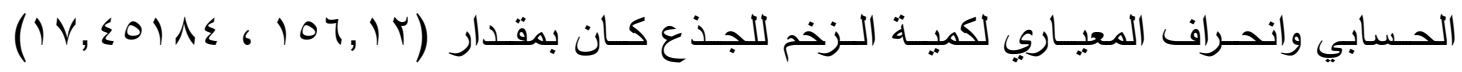

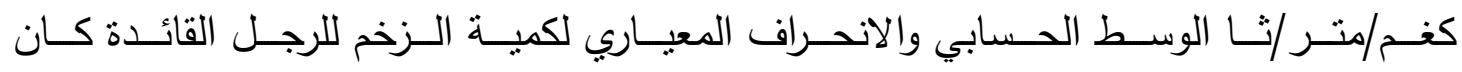

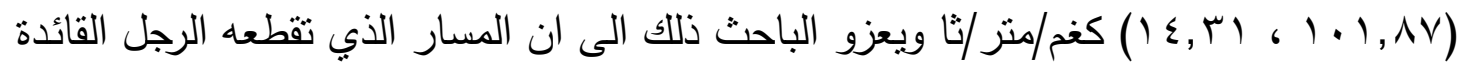

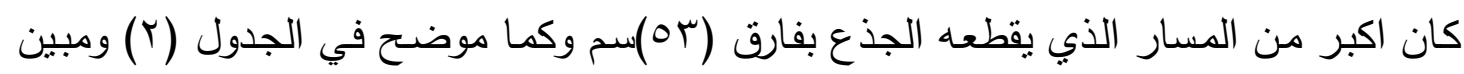

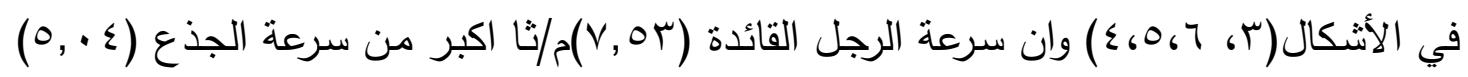

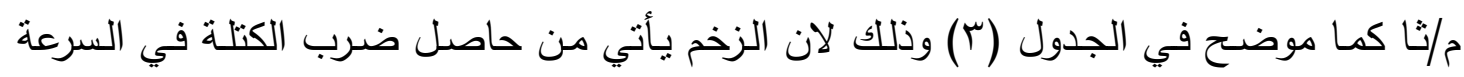

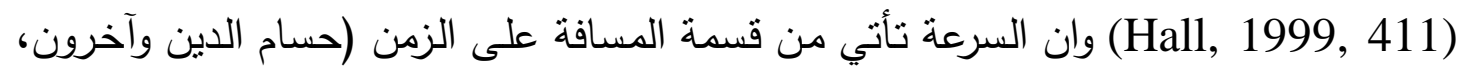

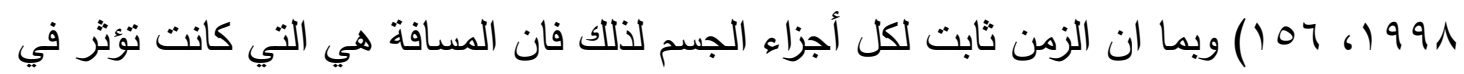

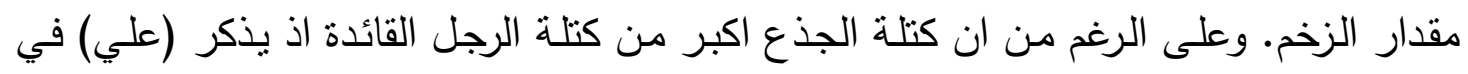

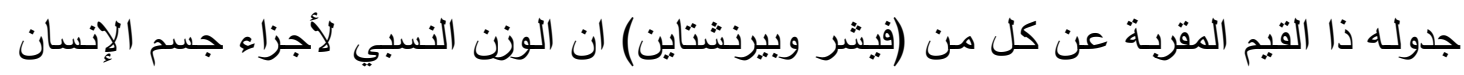

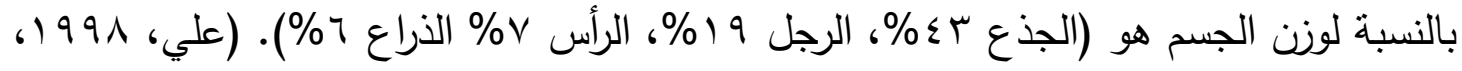
.$(10)$

في حين جاءت الذراع المعاكسة للقدم القائدة في المرتبة الثالثنة ثم الذراع المعاكسة للقدم

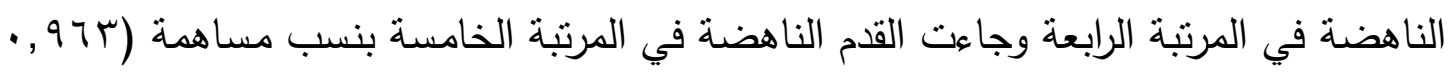

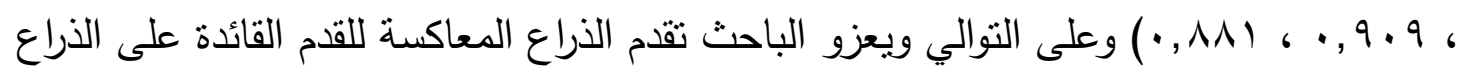
المعاكسة للقدم الناهضة بسبب طول المسار الذي قطعته الذراع المعاكسة للقدم القائدة وبفارق 


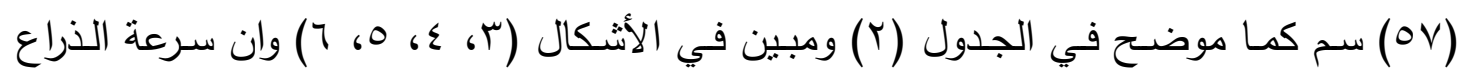

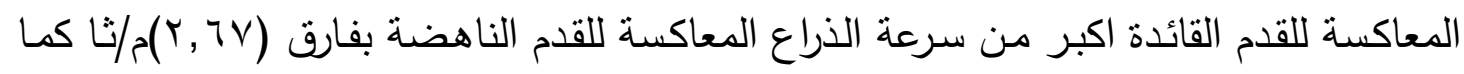
موضح في الجدول (r) وان إفراد عينة البحث من النوع الذين يستخدمون حركة الذراعين التي

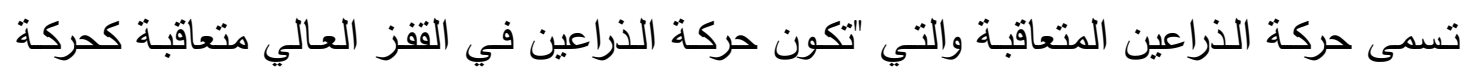

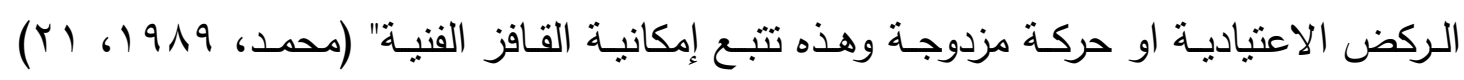
وبالتالي سوف يكون مسار الذراع المعاكسة للقدم القائدة اكبر من مسار الذابة الذاع المعاكسة للقدم

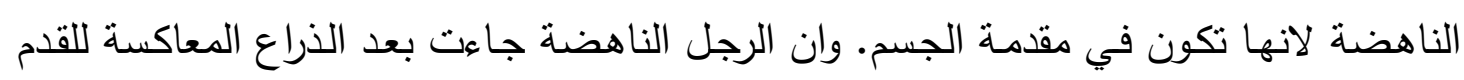

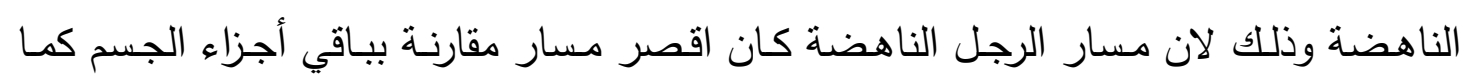

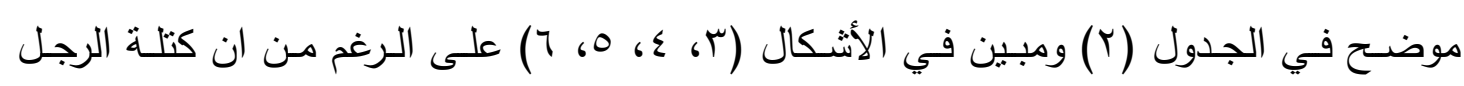

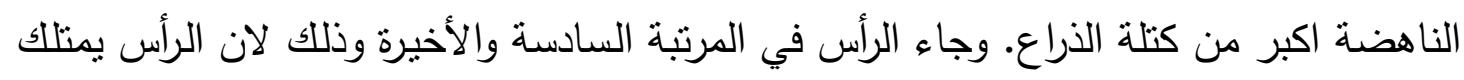

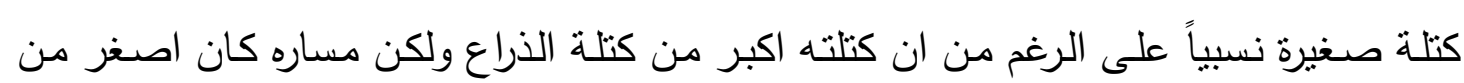
مسار الذراعين ، ولكن مسار الذراعين تغلب على مسار الرأس ولهذا جاء الرأس في المرتبة كلية الأخيرة.

مما تقدم ينضح ان المسار كان يؤثر في الزخم لان المسافة تؤثر في السرعة والسرعة تؤثر

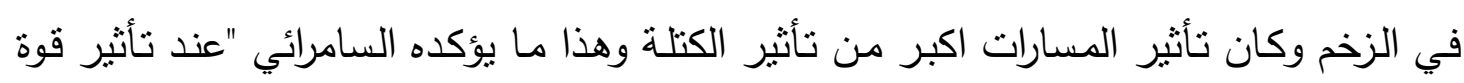

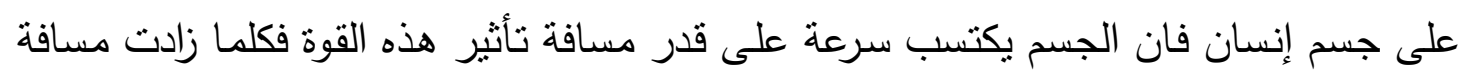
تأثير القوة ازدادت سرعة الجسم النهائية والعكس صحيح ـ لذا فمن المهم في الثناء مرحلة الارتقاء

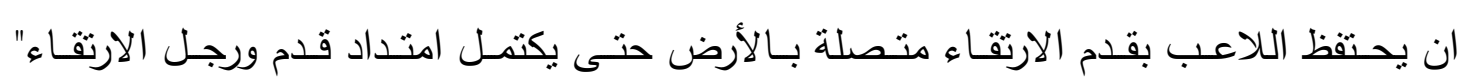

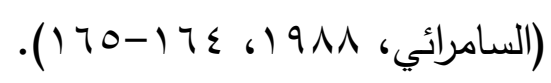

0ـ الاستنتاجات و التوصيات : الاستناجات :

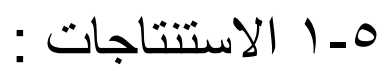

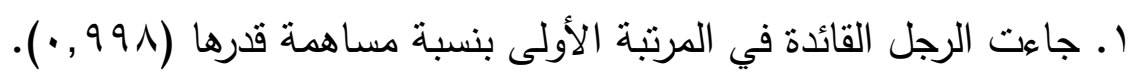

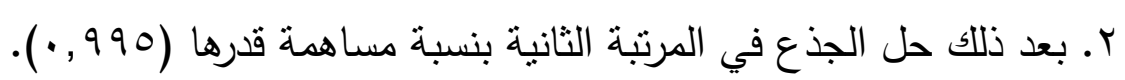

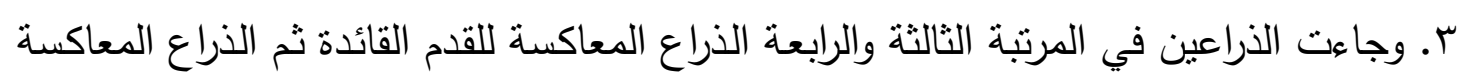

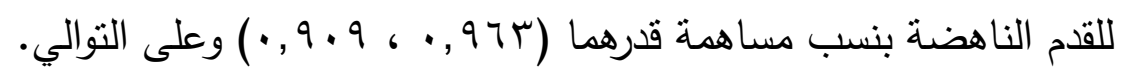

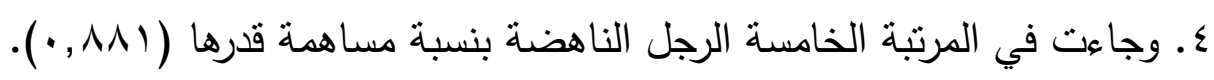

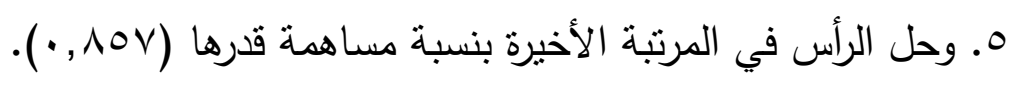




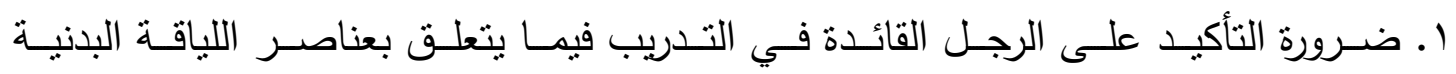

$$
\text { و (التكنيك) اذ يؤكد اغلب المدربين على قدم الارتقاء. التهاء }
$$

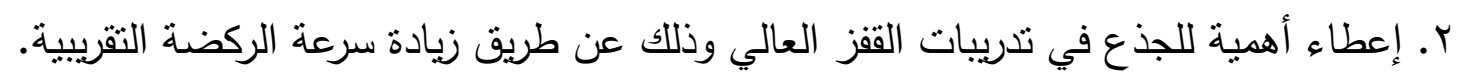
r. ضرورة التركيز على تدريبات التوافق بين حركة الرجل القائدة والذراعين.

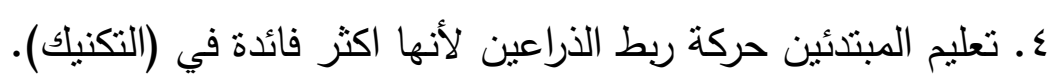

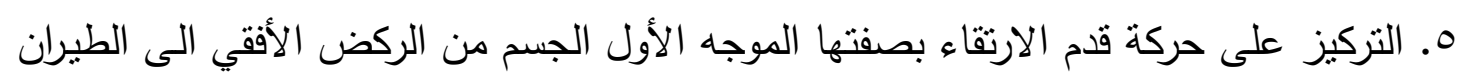
العمودي.

\section{المصادر العربية و الأجنبية :}

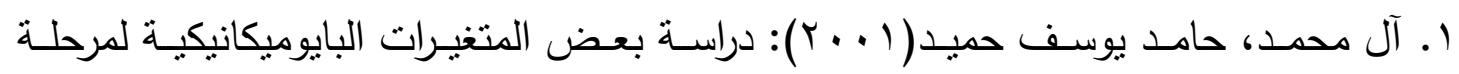

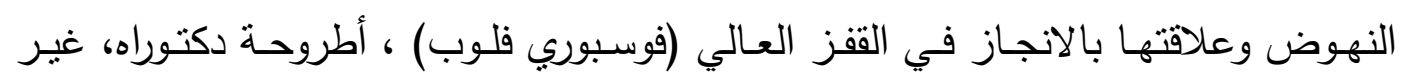

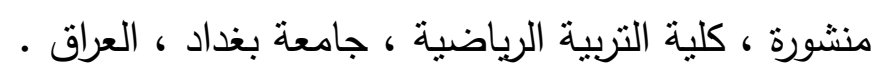

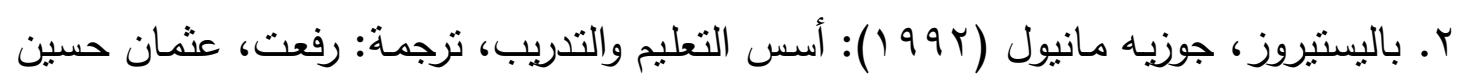

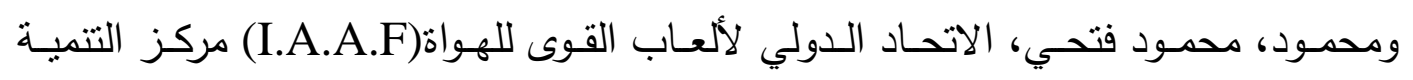

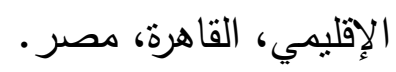

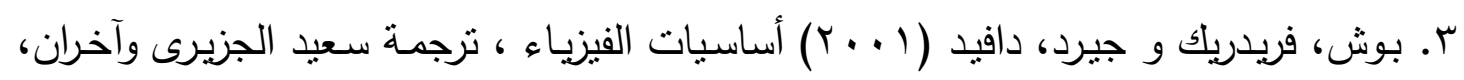

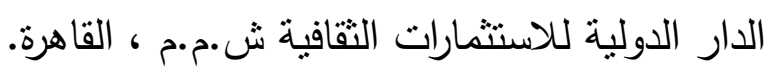

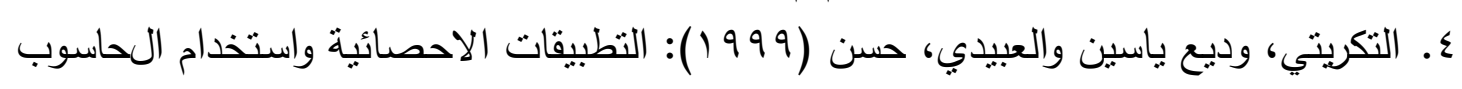

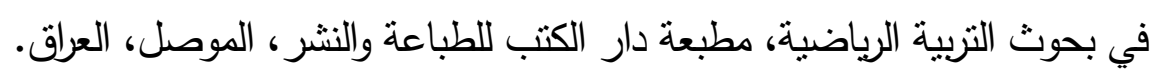

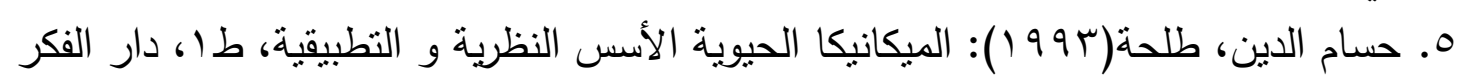

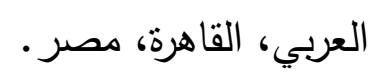
7. حسام الدين، طلحة، وأخرون (991 (1)): علم الحركة التطبيقي، طا، مركز الكتاب للنشر،

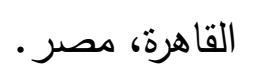
V. حسين، قاسـم حسن (999 (199): فعاليـات الوثب والقفز، ط ا، دار الفكر للطباعـة والنشر

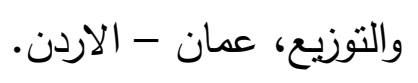
^. حسين، قاسم حسن وآخران( (999 ()): تحليل الميكانيكية الحيوية في فعاليات العاب الساحة

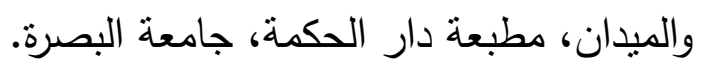

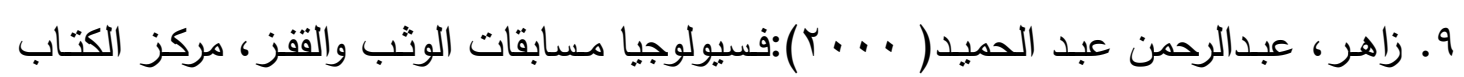

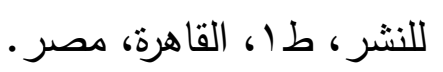

\section{roo}


• (ـ السامرائي، فواد نوفيق(9/1 ()): البايوميكانيك، دار الكتب للطباعة والنشر ، جامعة الموصل.

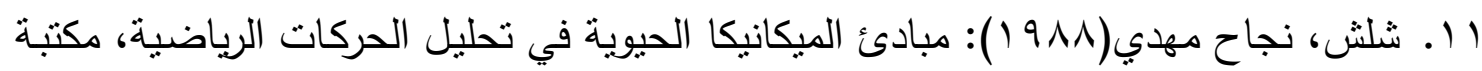
دار الكتب للطباعة والنشر ، جامعة الموصل، الموصل.

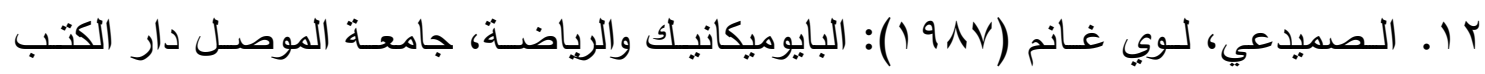

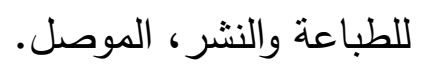

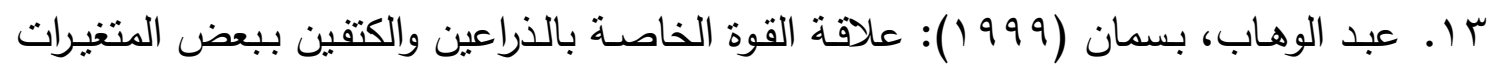
الكينماتيكية أثناء أداء بعض المهان (وهارات على جهاز المتوازي، أطروحة دكتوراه، كلية التربية

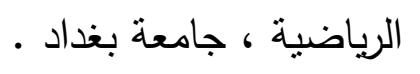

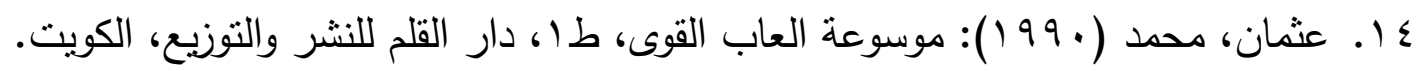

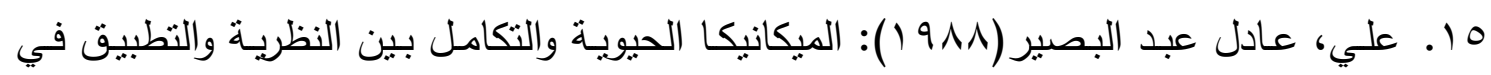
المجال الرياضي، طب، مركز الكتاب للنشر، القاهرة.

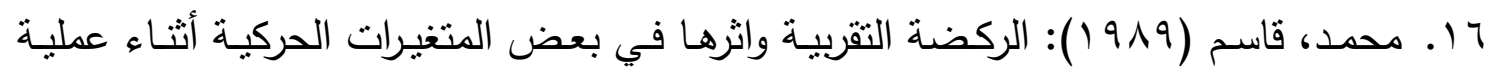

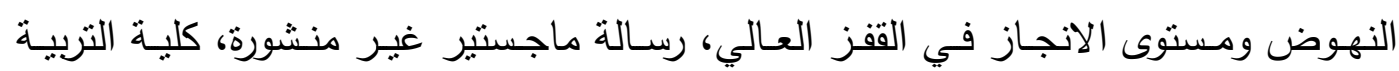

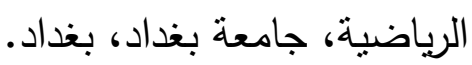

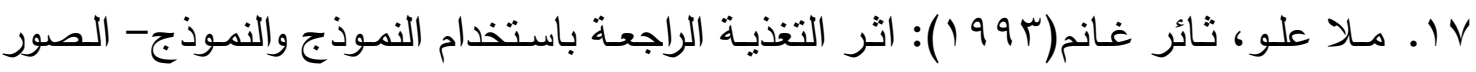

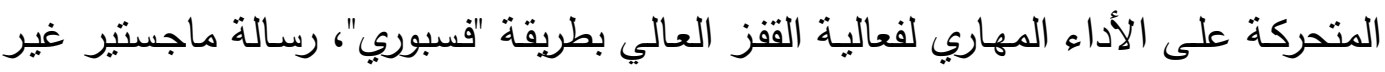

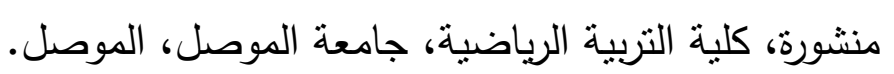

18. Carr , Gerry (1997): Mechanic Of Sport: A Practitioner's Guide, Human kinetics, USA

19. Hall J. Susan (1999), Basic Biomechanics , 3ed , Mc GRAW-HILL international editions, edition Boston.

20. Jacoby, ED and Fraley, Bod (1995): Complete Book of Jumps, Human Kinetics, USA.

21. New Studies in Athletics (1986): The I.A.A.F. Quarterly Magazine for: Technical research, Coaching information and Bibliographic Documentation.

22. Scholes, Gorden (1978): Field Events, Sport - By - Step Guide For Coaching and Athletes, Championship Have and Field Series.

23. Lennartz, K. et al., (1997): Scientific Bulletin: High Jump, Translation: Arndt, T., IAF Biomechanics Research Project Athens, Athens. 